\title{
Analisis Faktor Prediksi Keberhasilan Traksi Servikal Berdasarkan Tercapainya Realignment Tulang Servikal Pada Evaluasi Foto Polos Servikal Lateral Serial Pasien Dengan Cedera Tulang Servikal Subaksial
}

\author{
Ahmad Faried, Muhammad Zafrullah Arifin, Rully Hanafi Dahlan, Firman Priguna Tjahjono \\ dan Agung Budi Sutiono
}

\begin{abstract}
Introduction: Cervical spine injury is the most feared spinal injury for physicians, patients and their families. All patients with unstable subaxial cervical spine injury must be managed by cervical traction and stabilization. Lateral cervical plain radiography remains standard diagnostic tools to evaluate the stability of the cervical spine structure and has a high diagnosis value in evaluating the success of the cervical traction. The success of the cervical traction could be predicted by observing the alignment of the cervical base on series lateral cervical spine plain $x$-ray.

Method: This retrospective study involve thirty patients subaxial cervical spine injury admitted to Emergency Unit-Dr. Hasan Sadikin Hospital in 2009-2013. This study use the logistic regression analysis with $p<0.05$ was considered to be significant and the confidence interval (CI) $95 \%$.

Result: The results of this study showed that the failure of cervical traction (closed reduction) mainly determined by interval admission time and facet lock (FL). The interval admission time $(p=0.015 ; 2-$ sided tail Pearson's chi-square) and distribution of FL showed significant results ( $p=0.001 ; 2-$ sided tail Fisher's exact test). Odds ratio whether FL is present or absent is 3.8; 95\% CI 0.5-27.1 with $p=0.001$.

Conclusion: It is concluded that inform concent regarding cervical traction failure is needed in subaxial cervical injury $>24$ hours, where in pasients with FL cervical traction trial is not needed, instead immediate definitive management (opened reduction) with the stabilization is recommended.

(J I Bedah Indones. 2014;43:36-42).
\end{abstract}

Keyworlds: Subaxial cervical spinal injury, patient's charactheristic, cervical traction, evaluation of series lateral cervical spine plain $x$-ray.

\begin{abstract}
Abstrak
Pendahuluan: Cedera tulang servikal merupakan cedera tulang belakang yang paling ditakuti, baik bagi dokter, pasien dan keluarganya. Semua pasien dengan cedera tulang servikal subaksial yang tidak stabil, harus segera dilakukan fiksasi menggunakan traksi servikal. Foto polos servikal lateral masih merupakan standar dalam menganalisis stabilitas stuktur tulang servikal dan masih memiliki nilai diagnostik tinggi dalam mengevaluasi keberhasilan traksi servikal pasien cedera tulang servikal. Keberhasilan traksi servikal dapat diprediksi dengan melihat tercapainya realignment tulang servikal berdasarkan evaluasi foto polos servikal lateral serial pada pasien cedera tulang servikal subaksial.

Metode: Penelitian ini merupakan studi retrospektif yang dilakukan terhadap 30 pasien cedera tulang servikal subaksial yang masuk Unit Gawat Darurat (UGD) Rumah Sakit dr. Hasan Sadikin Bandung (RSHS) periode 2009-2013. Studi ini menggunakan metode statistik logistik regresi dengan kemaknaan berdasarkan nilai $\mathrm{p}<$ 0,05 dan confidence interval sebesar $95 \%$.

Hasil: Studi ini menunjukkan bahwa dari semua karakteristik pasien cedera servikal subaksial yang dilakukan traksi servikal (closed reduction), didapatkan interval kedatangan ke rumah sakit dan facet lock (FL) merupa-

Alamat Korespondensi

Ahmad Faried, dr., PhD

Departemen Bedah Saraf, FK UNPAD-RSHS

Email: Faried. fkup@gmail.com kan faktor utama suatu kegagalan traksi servikal. Interval kedatangan pasien ke RSHS pada keberhasilan traksi servikal bermakna signifikan secara statistik $(\mathrm{p}=0.015 ; 2-$ sided tail dengan Pearson's chi-square)
\end{abstract}


dan distribusi FL pada keberhasilan traksi servikal bermakna signifikan secara statistik ( $\mathrm{p}=0,001 ; 2-$ sided tail dengan Fisher's exact test). Odds ratio untuk ada atau tidak adanya FL adalah 3,8 dengan 95\% confidence interval 0.5-27.1; dengan $\mathrm{p}=0,001$.

Kesimpulan: Disimpulkan bahwa dalam penanganan dan terapi cedera servikal subaksial $>24$ jam perlu di-informed concent-kan akan kegagalan upaya traksi, serta bilamana terdapat FL tidak perlu dilakukan suatu upaya traksi servikal (closed reduction) percobaan, melainkan harus langsung dilakukan terapi definitif (opened reduction) serta stabilisasi (J I Bedah Indones. 2014;43:36-42).

Kata kunci: Cedera tulang servikal subaksial, karakteristik pasien, traksi servikal, evaluasi foto polos servikal lateral serial.

\section{Pendahuluan}

Cedera tulang servikal merupakan cedera tulang belakang yang paling ditakuti, baik bagi dokter, pa sien dan keluarganya, dimana terdapat korelasi antara tingkatan cedera dengan angka kecacatan dan atau angka kematiannya, semakin tinggi tingkatan cedera yang dialami penderita semakin tinggi angka kecacatan dan atau angka kematiannya. Kurang lebih 3,9\% pasien cedera kepala ringan pada kecelakaan lalulintas mendapat suatu cedera serius terhadap tulang servikal. ${ }^{1}$ Serta sekitar kurang lebih $17 \%$ pasien terlambat didiagnosis dengan cedera tulang servikal, dengan resiko munculnya defisit neurologis sebesar $29 \%^{2,3}$ Tingkat kejadian cedera tulang servikal pertahun dilaporkan 64/100,000 penduduk dengan dua puncak usia, satu didekade kedua dan ketiga dari penduduk laki-laki kemudian satu lagi pada wanita usia lanjut. Mekanisme paling umum dari cedera tulang servikal adalah terjatuh dari ketinggian, dengan mekanisme kompresi vertikal atau dikenal juga dengan aksialloading, diikuti dengan dengan kecelakaan kendaraan bermotor yang paling umum kedua. Dalam studi lain, yang merupakan uji coba multi-center terbesar sampai saat ini; cedera paling umum adalah atlantoaksial, dengan cedera paling sering ditulang servikal subaksial level C6 dan C7. ${ }^{4}$ Meskipun beberapa data-data menunjukan hasil yang mengejutkan, yaitu sejumlah pasien yang cedera secara klinis mengalami cedera tulang servikal ringan, mereka tetap merupakan ce dera paling umum dari cedera tulang belakang (spinal cord injury, disingkat dengan SCI) yang mewakili $55 \%$ dari semua kasus SCI. ${ }^{5}$

Foto polos servikal lateral masih merupakan standar dalam menganalisis stabilitas stuktur tulang servikal dan dirasakan masih memiliki nilai diagnostik tinggi dalam mengevaluasi keberhasilan traksi servikal pa sien cedera tulang servikal. ${ }^{6}$ Semua pasien dengan cedera tulang servikal subaksial yang tidak stabil, harus segera dilakukan fiksasi menggunakan traksi servikal. Walaupun pada beberapa pasien tindakan traksi servikal serta immobilisasi yang lama berhasil dengan baik, pada pasien sisanya tidak tercapai stabilisasinya dan memerlukan tindakan operatif.

Dikarenakan pentingnya suatu tindakan traksi servikal dalam penanganan cedera tulang servikal subaksial serta, sepanjang pengetahuan kami, belum adanya kepustakaan yang menganalisis faktor-faktor yang mempengaruhi keberhasilan traksi servikal de ngan menggunakan parameter keberhasilanya hanya dengan melihat tercapainya realignment tulang servikal berdasarkan evaluasi foto polos servikal lateral. Secara umum disebutkan, keberhasilan reduksi tertutup cedera servikal berkisar $64-91 \%$ dilihat dari perbaikan malalignment-nya. ${ }^{7}$ Studi ini di tujukan untuk menganalisis faktor apa saja yang dapat memprediksi keberhasilan traksi dari pemeriksaan radiologis sederhana dirumah sakit dengan fasilitas, sumber daya serta keadaan sosio-ekonomi masyarakat yang terbatas.

\section{Metode}

Penelitian ini merupakan suatu studi retrospektif analitik, dengan melakukan pengumpulan data rekam medis penderita dewasa dengan cedera tulang belakang servikal yang membutuhkan traksi servikal yang datang ke Unit Gawat Darurat (UGD) Rumah Sakit Dr. Hasan Sadikin (RSHS), Bandung dari tahun 2009-2013 dan setuju untuk dilakukan foto polos servikal lateral serial. Data penderita yang dikumpulkan adalah karakteristik pasien dengan cedera tulang ser- 
vikal subaksial (usia, jenis kelamin, interval kejadian, jenis kecelakaan, GCS, diagnosis, jenis fraktur cedera tulang servikal, dan ada atau tidaknya facet lock) terhadap keberhasilan traksi dengan hanya melihat tercapainya realignment tulang servikal berdasarkan evaluasi foto polos tulang servikal lateral serial. Data dalam studi ini diolah dengan menggunakan metode statistik logistik regresi dengan kemaknaan berdasarkan nilai $\mathrm{p}<0,05$ dan confidence interval sebesar
$95 \%$.

\section{Hasil}

Sebanyak 30 subjek penelitian berusia 15-80 tahun (pasien dewasa), dengan cedera tulang belakang servikal yang membutuhkan traksi servikal (Gambar 1) yang datang ke RSHS, Bandung dari tahun 2009-2013 dan setuju untuk dilakukan foto polos servikal lateral telah diikutsertakan didalam penelitian ini (Tabel 1). Subjek pada studi ini sebanyak 30 orang pasien

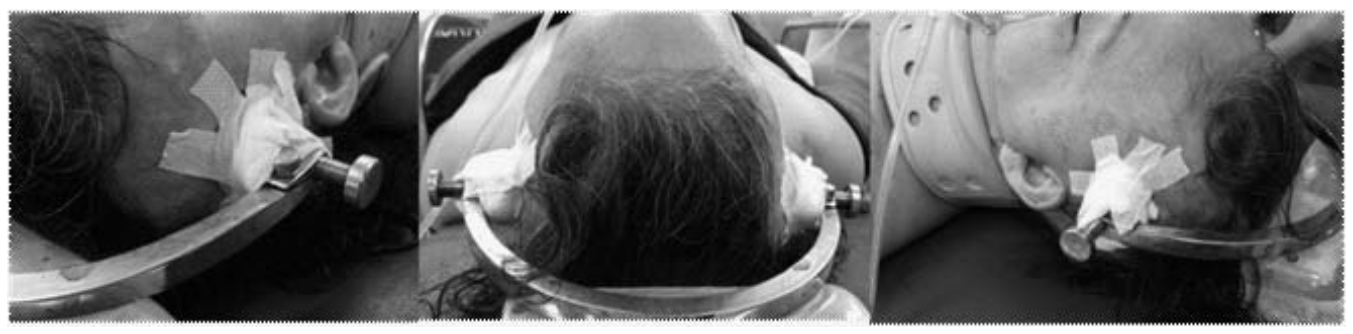

Gambar 1. Pasien dengan cedera tulang belakang servikal yang membutuhkan traksi servikal menggunakan Gardner-Wells tongs. Pin dipasang pada temporal ridge (cranial dari origo otot temporalis superfisialis), $\pm 2-3$ jari $(3-4 \mathrm{~cm})$ di atas pinna. Pada posisi netral, pin dipasang tepat diatas meatus acusticus externus (MAE), sejajar dengan sumbu longitudinal tulang servikal.

dengan kelompok usia terbanyak adalah usia 41-50 tahun sebanyak $8(26,6 \%)$ pasien. Sedangkan kelompok dengan jumlah terkecil pada kelompok usia $>70$ tahun sebanyak $1(6,7 \%)$ kasus; hal ini sangat berbeda dengan kelompok usia kecelakaan secara umum di UGD RSHS 2010-2011 dimana usia terbanyak adalah 11-20 (29\%) tahun.8 Jenis kelamin yang terbanyak pada penelitian ini adalah laki-laki sebanyak $24(80 \%)$ pasien. Sedangkan pasien perempuan berjumlah sebanyak 6 pasien (20\%).

Interval waktu terbanyak kedatangan pasien pada sampel penelitian ini adalah $>48$ jam sebanyak 10 $(33,3 \%)$ pasien. Sedangkan interval waktu tersedikit pada sampel penelitian ini adalah $<6$ jam sebanyak 5 $(16,6 \%)$ pasien; dimana interval kedatangan $>48$ jam dua kali lipat dari interval $<6$ jam. Jenis kecelakaan terjatuh dari ketinggian merupakan kasus terbanyak pada sampel penelitian ini sebanyak 19 (63,3\%) pasien. Sedangkan kasus kecelakaan lalu lintas (KLL) pada sampel penelitian ini adalah $11(36,6 \%)$ pasien. Kasus cedera servikal dengan GCS 14-15 sebanyak $26(87 \%)$ pasien dan GCS 9-13 sebanyak 4 (13\%) pasien. GCS > 13 merupakan kasus terbanyak pada sampel penelitian ini sebanyak $28(93,3 \%)$ pasien. Sedangkan GCS $<13$ sebanyak $2(6,6 \%)$ pesien; dimana distribusi GCS pada suatu keberhasilan traksi servikal tidak bermakna secara statistik; data me ngenai GCS pada kecelakaan secara umum di UGD RSHS 2010-2011 adalah GCS 14-15 sebanyak 74\%, GCS 9-13 sebanyak 19\% dan GCS $<8$ sebanyak 9\%. Odds ratio $(\mathrm{OR})$ untuk GCS $(<13 />13)$ adalah 1.000 dengan 95\% confidence interval (CI) 0,057-17,621; yang tidak bermakna secara statistik.

Diagnosis dengan Frankel A merupakan kasus terbanyak pada sampel penelitian ini sebanyak $13(43,3 \%)$ pasien, diikuti dengan Frankel B sebanyak 12 (40\%) pasien, Frankel C sebanyak 2 (6.6\%) pasien, dan Frankel D sebanyak $2(6,6 \%)$ pasien. Sedangkan Frankel E sebanyak 1 (3.3\%) pasien merupakan kasus tersedikit. Jenis fraktur burst dan none merupakan kasus terbanyak pada sampel penelitian ini, masing-masing sebanyak $9(30 \%)$ pasien, diikuti dengan fraktur dislok sebanyak $7(23,3 \%)$ pasien, fraktur linear seba nyak $3(10 \%)$ pasien, dan fraktur kompres sebanyak $2(6.6 \%)$ pasien.

Jumlah pasien dengan facet lock (FL) berbanding 
Tabel 1. Karakteristik pasien cedera servikal subaksial terhadap keberhasilan traksi dengan hanya melihat tercapainya realignment tulang servikal berdasarkan evaluasi foto polos tulang servikal lateral serial.

\begin{tabular}{|c|c|c|c|c|}
\hline \multirow[t]{2}{*}{ Karakteristik Sampel } & \multicolumn{2}{|c|}{ Keberhasilan Traksi } & \multirow{2}{*}{ Total } & \multirow{2}{*}{$p$ Value } \\
\hline & Malalignment & Realignment & & \\
\hline \multicolumn{5}{|l|}{ Usia (tahun) } \\
\hline$<20$ & 0 & $5(33.3 \%)$ & 5 & \multirow{7}{*}{0.079} \\
\hline $21-30$ & $5(33.3 \%)$ & 0 & 5 & \\
\hline $31-40$ & $2(13.3 \%)$ & $2(13.3 \%)$ & 4 & \\
\hline $41-50$ & $4(26.7 \%)$ & $4(26.7 \%)$ & 8 & \\
\hline $51-60$ & $2(13.3 \%)$ & $1(6.7 \%)$ & 3 & \\
\hline $61-70$ & $2(13.3 \%)$ & $2(13.3 \%)$ & 4 & \\
\hline$>70$ & 0 & $1(6.7 \%)$ & 1 & \\
\hline \multicolumn{5}{|l|}{ Jenis Kelamin } \\
\hline Laki-laki & $12(80 \%)$ & $12(80 \%)$ & 24 & \multirow{2}{*}{0.674} \\
\hline Perempuan & $3(20 \%)$ & $3(20 \%)$ & 6 & \\
\hline \multicolumn{5}{|l|}{ Interval } \\
\hline$<6$ jam & $1(6.7 \%)$ & $4(26.7 \%)$ & 5 & \multirow{4}{*}{$0.015 *$} \\
\hline $6-24$ jam & $4(26.7 \%)$ & $4(26.7 \%)$ & 8 & \\
\hline $24-48$ jam & $7(46.7 \%)$ & 0 & 7 & \\
\hline$>48$ jam & $3(20 \%)$ & $7(46.7 \%)$ & 10 & \\
\hline \multicolumn{5}{|l|}{ Jenis Kecelakaan } \\
\hline Jatuh & $10(66.7 \%)$ & $9(60 \%)$ & 19 & \multirow{2}{*}{0.5} \\
\hline KLL & $5(33.3 \%)$ & $6(40 \%)$ & 11 & \\
\hline \multicolumn{5}{|l|}{ GCS } \\
\hline $15-13$ & $14(93.3 \%)$ & $14(93.3 \%)$ & 28 & \multirow{2}{*}{0.759} \\
\hline $12-.3$ & $1(6.7 \%)$ & $1(6.7 \%)$ & 2 & \\
\hline \multicolumn{5}{|l|}{ Diagnosis } \\
\hline Frankel A & $9(60 \%)$ & $4(26.7 \%)$ & 13 & \multirow{5}{*}{0.358} \\
\hline Frankel B & $4(26.7 \%)$ & $8(53.3 \%)$ & 12 & \\
\hline Frankel C & $1(6.7 \%)$ & $1(6.7 \%)$ & 2 & \\
\hline Frankel D & $1(6.7 \%)$ & $1(6.7 \%)$ & 2 & \\
\hline Frankel E & 0 & $1(6.7 \%)$ & 1 & \\
\hline \multicolumn{5}{|l|}{ Jenis Fraktur } \\
\hline None & $9(60 \%)$ & 0 & 9 & \multirow{5}{*}{0.55} \\
\hline Burst & $2(13.3 \%)$ & $7(46.7 \%)$ & 9 & \\
\hline Dislok & $3(20 \%)$ & $4(26.7 \%)$ & 7 & \\
\hline Linear & 0 & $2(13.3 \%)$ & 2 & \\
\hline Kompres & $1(6.7 \%)$ & $2(13.3 \%)$ & 3 & \\
\hline \multicolumn{5}{|l|}{ Facet Lock } \\
\hline Tidak ada & $3(20 \%)$ & $13(86.7 \%)$ & 16 & \multirow{2}{*}{$0.001 *$} \\
\hline Ada & $12(80 \%)$ & $2(13.3 \%)$ & 14 & \\
\hline Total & 15 & 15 & 30 & \\
\hline
\end{tabular}

KLL: kecelakaan laulintas, GCS: Glasgow coma score, *: bermakna 
pasien dengan tanpa FL tidak jauh berbeda yaitu 14 vs. 16; Dengan perincian sebagai berikut:

1. Pasien dengan FL yang tidak tercapai alignmentnya (malalignment) sebanyak 12 (80\%) kasus; Pasien dengan FL yang tercapainya alignmentnya (realignment) sebanyak $2(13,3 \%)$ kasus.

2. Pasien tanpa FL yang tidak tercapai alignment-nya (malalignment) ada 3 (20\%) kasus; Pasien tanpa FL tercapai alignment-nya (realignment) sebanyak $13(86,7 \%)$ kasus.

\section{Pembahasan}

Penelitian mengenai cedera servikal di Indonesia sangatlah menarik untuk diteliti mengingat 3,9\% pasien dengan cedera kepala pada kasus-kasus kecelakaan yang ditangani di UGD RSHS antara 2010-2011 berpotensi mengalami cedera serius terhadap tulang servikalnyal dan hingga saat ini belum adanya laporan mengenai faktor-faktor prediksi keberhasilan suatu tindakan traksi servikal pada populasi penduduk Indonesia dengan cedera servikal, di Bandung pada khususnya.

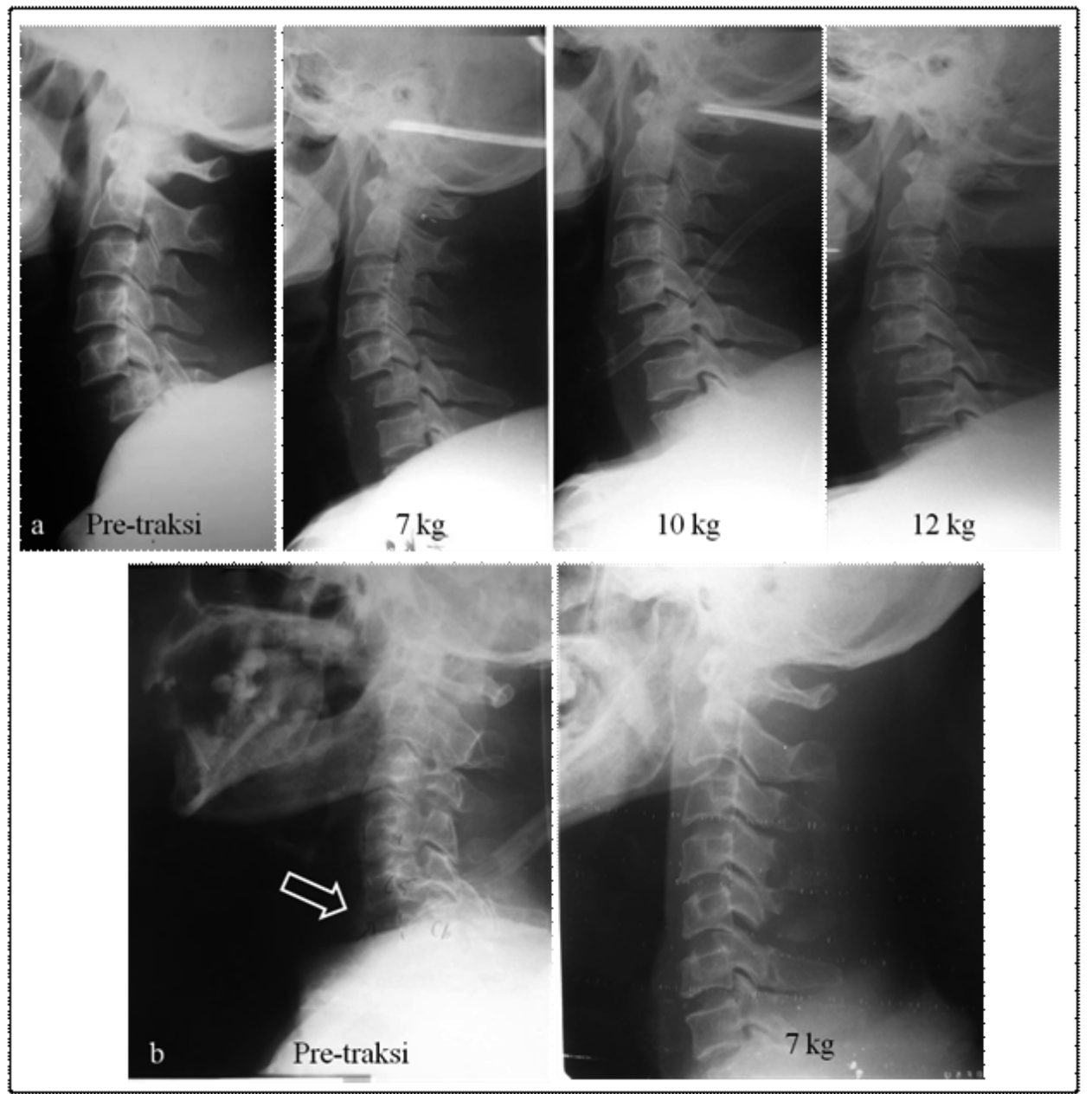

Gambar 2. Keberhasilan traksi servikal dilihat dengan tercapainya realignment tulang servikal, berdasarkan evaluasi foto polos servikal lateral serial pasien cedera tulang servikal subaksial. (A) Pasien yang dilakukan traksi servikal namun tidak tercapai alignment-nya (malalignment). (B) Pasien yang dilakukan traksi servikal tercapai alignment-nya (realignment). Panah menunjukan facet lock pada servikal-6 (C6).

Rentang usia pasien cedera servikal berkisar antara 15-80 tahun, dengan rata-rata $41,47 \pm 16,75$; data ini sangat berbeda dengan rata-rata usia pada kecelakaan secara umum di UGD RSHS 2010-2011 yaitu
$28,55 \pm 16,4$. Perbedaan rata-rata usia ini dapat dijelaskan dengan melihat kerentanan struktur anatomis tulang dan otot servikal orang tua yang jauh menurun dibandingkan pasien dengan usia yang lebih muda. 
Distribusi usia pada keberhasilan traksi servikal (Gambar 2A-B), tidak bermakna secara statistik. Distribusi jenis kelamin pada suatu keberhasilan traksi servikal tidak bermakna secara statistik; data ini tidak jauh berbeda dengan jenis kelamin pada kecelakaan secara umum di UGD RSHS 2010-2011 laki-laki sebanyak $74 \%$ dan perempuan $26 \%$ pasien. Odds ratio (OR) untuk jenis kelamin (laki-laki per perempuan) adalah 1.000 dengan $95 \%$ confidence interval (CI) $0,167-5,985$ yang tidak bermakna secara statistik.

Rentang interval pada studi ini berkisar 1-720 jam, dengan rata-rata 93,2 $\pm 154,41$ jam atau sekitar 3.8 hari. Dimana distribusi interval kedatangan pasien ke RSHS pada keberhasilan traksi servikal bermakna signifikan secara statistik ( $\mathrm{p}=0,015$; bivariate analysis). Hal ini sesuai dengan studi oleh Gallie9 dan Argenson dkk,10 menyatakan pasien dengan cedera kepala yang terlambat ditangani atau diterapi (interval kedatangan sampai ke RS $>24$ jam) memiliki kecendrungan kegagal traksi hingga 22,5\%, terutama disebabkan oleh semakin bertambahnya spastisitas otot-otot servikal. Distribusi jenis kecelakaan pada suatu keberhasilan traksi servikal tidak bermakna secara statistik; data ini berbeda dengan jenis kecelakaan pada kecelakaan secara umum di UGD RSHS 2010-2011 dimana terjatuh dari ketinggian sebanyak $14 \%$ dan KLL sebanyak 55,2\% pasien. Odds ratio (OR) untuk jenis kecelakaan (jatuh/ KLL) adalah 1,333 dengan 95\% confidence interval (CI) $0,301-$ 5,915; yang tidak bermakna secara statistik.

Data mengenai diagnosis cedera servikal oleh Kumar dkk11: Frankel A sebanyak 40\%, Frankel B sebanyak 20\%, Frankel C sebanyak 27\% dan Frankel D sebanyak $13 \%$ pasien. Dimana diagnosis pada suatu keberhasilan traksi servikal di RSHS adalah Frankel A 43,3\%, Frankel B 40\%, Frankel C 6.6\%, Frankel D 6\% dan Frankel E 3.3\%, yang tidak bermakna secara statistik. Jenis fraktur pada suatu keberhasilan traksi servikal tidak bermakna secara statistik. Cedera servikal paling umum pada servikal subaksial yaitu pada level C6 dan C7.4 Pada studi ini didapatkan ce dera terbanyak pada level C5 sebanyak 6 (20\%), diikuti C5-C6 sebanyak 4 (13.3\%), C4-C5 dan C6-C7 masing-masing $3(10 \%)$ pasien.

Distribusi FL pada suatu keberhasilan traksi servikal bermakna signifikan secara statistik $(\mathrm{p}=0.001 ;$ biva riate analysis). Odds ratio $(\mathrm{OR})$ untuk ada atau tidak adanya FL adalah 3,8 dengan 95\% confidence interval (CI) 0,5-27,1; yang bermakna signifikan secara statistik $(\mathrm{p}=0,001)$. Hasil analisis dengan menggunakan multiple logistic regression menunjukkan faktor yang paling dominan yang berhubungan dengan keberhasilan traksi, yang dilihat dari evaluasi foto polos servikal lateral serial, adalah FL, yang mengindikasikan kegagalan traksi servikal 3.8 kali lebih tinggi bila terdapat FL dibandingkan pasien yang tidak terdapat FL. Dengan terdapatnya facet lock, diperkirakan kegagalan traksi meningkat menjadi 26\%; motalitasnya meningkat menjadi 7\%; unilateral FL memiliki kecendrungan terjadi kegagalan traksi lebih tinggi dibandingkan dengan bilateral FL. ${ }^{11}$ Terdapat kerusakan ligamen-ligamen yang menyertainya sebagai salah satu faktor penyulit dari proses realignmentnya. ${ }^{11,12}$

\section{Kesimpulan}

Secara keseluruhan, hasil studi ini menunjukkan bahwa semua karakteristik pasien dengan cedera servikal subaksial yang dilakukan traksi servikal (closed reduction), didapatkan bahwa interval kedatangan dan FL merupakan faktor utama suatu kegagalan traksi servikal. Hasil ini menyarankan agar dalam penanganan dan terapi cedera servikal subaksial diatas 24 jam perlu di-informed concent-kan akan kegagalan traksi; serta bilamana terdapat FL tidak perlu di lakukan upaya traksi servikal (closed reduction) percobaan, melainkan harus langsung dilakukan terapi definitif berupa opened reduction dengan stabilisasi.

\section{Daftar Pustaka}

1. Arifin, MZ, Gunawan W. Correlation of cervical injury to frontal depressed fracture in mild head injury. Bandung Medical Journal 2011;43:122-7.

2. Greenberg S. Handbook of neurosurgery, 7th ed. New York 2010. Thieme.

3. Thomas W. Fracture frontal. Updated 6-3-2008. Cited: 1 Januari 2014. http://emedicine.medscape.com/article/825169-overview.

4. Goldberg W, Mueller C, Panacek E, Tigges S, Hoffman JR, Mower WR, et al. Distribution and patterns of blunt traumatic cervical spine injury. Ann Emerg Med. 2001;38:17-21. 
5. Sekhon LH, Fehlings MG. Epidemiology, demographics and patho-physiology acute spinal cord injury. Spine 2001;26:S2-12.

6. Miller CP, Sabino J, Bibble JE, Whang PG, Grauer JN. Oblique radiographs compared favorably with computed tomography images in assessing cervical foraminal area. Am J Orthop. 2011;40:241-5.

7. Lemons VR, Wagner FC Jr. Stabilization of subaxial cervical spinal injuries. Surg Neurol. 1993;39:511-8.

8. Profil Karakteristik Pasien yang datang ke Unit Gawat Darurat (UGD) RS Dr. Hasan Sadikin (RSHS), Bandung, Jawa Barat, 2010-2011.

9. Gallie WE. Skeletal traction in the treatment of fractures and dislocations of the cervical spine. Ann Surg. 1937;106:7706.

10. Argenson C, Lovet J, Sanouiller JL, de Peretti F. Traumatic rotatory displacement of the lower cervical spine. Spine 1988;13:767-73.

11. Kumar R, Arora S, Mohapatra D. Cervical spine injury recovery prediction scale: A means of predicting neurological recovery in patients with acute subaxial cervical spine injury. Journal of Orthopaedic Surgery 2011;19:25-9.

12. Pollard ME, Apple DF. Factors associated with improved neurologic out comes in patients with incomplete tetraplegia. Spine 2003;28:33-9. 